\title{
SUBSÍDIOS PARA A GESTÃO DO PATRIMÔNIO ARQUEOLÓGICO DO MUNICÍPIO DE GOIANA, PERNAMBUCO, BRASIL
}

\author{
Milena Duarte de Oliveira Souza \\ Maristela Casé Costa Cunha ${ }^{* *}$
}

RESUMO: O município de Goiana (PE) tem experimentado uma nova fase de expansão com a instalação de indústrias de grande porte, na última década. Do ponto de vista do patrimônio arqueológico, cenários de expansão e crescimento remetem a riscos de destruição de bens finitos e não renováveis. Os impactos do processo de expansão ocorrem na área urbana, particularmente no centro histórico tombado, e também na área rural, onde tais riscos se potencializam. Remetem essencialmente à expansão industrial em áreas antes ocupadas por campos de cultivo de cana de açúcar e desconhecidas do ponto de vista arqueológico. A adoção de uma Gestão do Patrimônio Arqueológico (GPA) no âmbito municipal tem demonstrado, em outros municípios brasileiros, que a prevenção de impactos e a preservação dos bens arqueológicos podem ser alcançadas por meio de instrumentos de identificação, documentação, proteção e promoção. A análise de instrumentos voltados para a GPA do município de Goiana, à luz de outras experiências municipais e estaduais, constitui a tônica deste estudo. Foram analisados 13 instrumentos de gestão, dos quais 8 não são aplicados em Goiana, e 5 são parcialmente aplicados ou apresentam falhas de execução. A análise apontou o desconhecimento das responsabilidades municipais em tal setor, além da ausência ou a ineficiência de alguns instrumentos do sistema da GPA.

Palavras-chave: Patrimônio arqueológico; gestão arqueológica; Goiana-PE..

ABSTRACT: The city of Goiana (PE) has experienced a new phase of expansion with the installation of large industries, in the last decade. From the point of view of the archaeological heritage, expansion and growth scenarios refer to the risk of destruction of finite and nonrenewable assets. The impacts of the expansion process occur the urban area, particularly in the historic center tumbled, so in rural areas, such risks are potentiated. It refers primarily to industrial expansion in areas previously occupied by cultivated fields of sugar cane and the unknown archaeological point of view. However, the adoption of a Management of the Archaeological Heritage (MAH) at the municipal level has been shown in other municipalities, the impact prevention and preservation of archaeological sites can be reached by means of instruments of identification, documentation, protection and promotion. The analysis of instruments designed for the MAH of the city of Goiana, in the light of other state and local experiences, is the keynote of this study. About 13 management tools were analyzed, while 8 are not applied, 5 are partially applied or fail of execution. The analysis aimed, among other issues, the lack of municipal responsibilities and powers in this sector. Also the absence or inefficiency of some system of instruments provided for MAH.

Keywords: Archaeological heritage; archaeological management; Goiana-PE. 


\section{Introdução}

Os riscos à preservação dos bens arqueológicos podem estar associados a diversas atividades humanas dos dias atuais, sobretudo à expansão urbana e industrial. Seguindo a tendência mundial de fomento às obras de infraestrutura, os Governos Federal e Estaduais brasileiros têm implantado, nas últimas décadas, inúmeros empreendimentos desenvolvimentistas nesta área. Neste contexto se destacam projetos de rodovias, portos, fábricas, usinas, entre tantos outros objetos de planos políticos e econômicos no País. Trata-se de empreendimentos que muitas vezes atingem áreas de abrangência de grandes dimensões, transpassando estados e municípios (Caldarelli e Santos, 1999-2000).

Esse estímulo à instalação de empreendimentos agravou a situação de risco do patrimônio arqueológico do País, sobretudo naquelas áreas desconhecidas do ponto de vista arqueológico, que passaram a ser efetivamente ocupadas, em ritmo acelerado. A situação experimentada, atualmente, no município de Goiana, no Estado de Pernambuco, representa esta tendência.

O patrimônio arqueológico, segundo a Carta de Lausanne, constitui testemunho essencial sobre as atividades humanas do passado (ICOMOS, 1990), e por esta razão deve ser estudado e protegido. Por outro lado, afirma que "as políticas de proteção ao patrimônio arqueológico devem ser consideradas pelos planificadores nos níveis nacional, regional e local". Portanto, os estados e municípios também têm competências estabelecidas quanto à proteção do patrimônio arqueológico. Trata-se de "responsabilidade compartilhada", atribuída pela Constituição da República Federativa do Brasil de 1988, que inclui também todos os cidadãos como corresponsáveis (Pardi, 2002).

Em âmbito federal (União), cabe ao Instituto do Patrimônio Histórico e Artístico Nacional IPHAN, proteger, fiscalizar, promover, estudar e pesquisar o patrimônio cultural brasileiro (Miranda, 2006), onde se inclui o arqueológico. Entre muitas atribuições, cabe ao IPHAN a gestão dos sítios arqueológicos localizados no território brasileiro. Desde 1997, os sítios passaram a ser registrados no Cadastro Nacional de Sítios Arqueológicos - CNSA, para fins de registro e proteção (IPHAN, 2014).

No âmbito estadual, a Constituição do Estado de Pernambuco, de 5 de outubro de 1989, estabelece no artigo 197, parágrafo $4^{\circ}$, que as "jazidas arqueológicas" ficam sob a proteção legal dos governos estadual e municipais (PERNAMBUCO, 2008). No que tange às formas de proteção dos bens arqueológicos, a legislação estadual parece eleger o tombamento como a melhor opção para as questões patrimoniais. Foi delegado ao Conselho Estadual de Cultura o dever de manter os livros de tombo do patrimônio cultural, entre eles o Livro de Tombo dos Bens Móveis de valor arqueológico, etnográfico, histórico, artístico ou folclórico. A Lei Estadual no 7.970 delegou ainda à Fundação do Patrimônio Histórico e Artístico de Pernambuco FUNDARPE - as incumbências de dar parecer técnico sobre tombamentos de bens, fiscalizar e verificar periodicamente o bem tombado (PERNAMBUCO, 1979). 
Em âmbito municipal, do ponto de vista da proteção legal do patrimônio arqueológico, segundo Cali (2005), compete ao município atuar em caráter suplementar, isto é, restrito ao aperfeiçoamento da legislação federal. Entretanto, do ponto de vista da competência material, de ordem político-administrativa, o Poder Público Municipal pode adotar um conjunto de ações que visem a proteção do patrimônio arqueológico, por meio de inventários, registros, vigilância, tombamento e desapropriação (Cali, 2005).

A legislação municipal adotada no município de Goiana expressa, sobretudo na sua Lei Orgânica, revisada e atualizada em 2010, (GOIANA, 1990) determina as competências municipais relativas ao patrimônio cultural e arqueológico em seu Art. 185: "Ao Município cumpre proteger os documentos, as obras e outros bens de valor histórico, artístico e cultural, os monumentos, as paisagens naturais notáveis e os sítios arqueológicos" (grifo nosso). A definição das competências de cada ente da Federação no tocante à proteção do patrimônio arqueológico, portanto, está prevista na legislação brasileira, em todos os níveis de competências administrativas.

O território que compreende o município poderá preservar, em seu solo e subsolo, parte de sua História nacional sob a forma de vestígios arqueológicos. Estudos arqueológicos realizados na área desde 1970 corroboram com esta afirmação (Albuquerque, et al., 1999). Desde aquela época, pesquisadores vinculados à Universidade Federal de Pernambuco têm buscado vestígios de ocupações dos primeiros habitantes do território, bem como de outros grupos que por ele passaram ou se fixaram. A partir do ano de 2005, as pesquisas na área se intensificaram em virtude dos processos de licenciamento ambiental visando a instalação de empreendimentos (Albuquerque, et al., 2012, 2011, 2008; Alves, 2007). Esses estudos permitiram a identificação de dezenas de sítios arqueológicos, que teriam sido destruídos ou ocultados pelas obras na ausência de pesquisadores. A realização de tais pesquisas, portanto, conduziu ao resgate de uma memória ocultada pelo tempo.

A par dos estudos arqueológicos o município está experimentando uma nova fase de crescimento com a instalação de indústrias de grande porte em três grandes setores: farmacoquímico, automotivo e vidreiro (PERNAMBUCO, 2010, 2011; EMPRESA BRASILEIRA DE HEMODERIVADOS E BIOTECNOLOGIA, 2013). É plausível prever a expansão dos setores industriais referidos acima, tendo em vista a necessidade de planejamento e infraestrutura, além do agenciamento de fornecedores para o mercado.

A Empresa Brasileira de Hemoderivados e Biotecnologia (Hemobrás), em parceria com o Centro de Pesquisa Aggeu Magalhães/Fiocruz, realizou recentemente uma análise socioambiental no município de Goiana (EMPRESA BRASILEIRA DE HEMODERIVADOS E BIOTECNOLOGIA, 2013), no intuito de subsidiar ações governamentais e comunitárias de cunho sustentável diante desse cenário de expansão. De acordo com a pesquisa, os dados de estudos ambientais relativos ao uso e ocupação urbano/industrial do solo no município encontram-se defasados. Ademais, há uma demanda urgente de revisão do Plano Diretor de Desenvolvimento Urbano do Município de Goiana (GOIANA, 2004), pois no documento vigente não há referências a esse processo de crescimento econômico impulsionado pela chegada de 
grandes empreendimentos (EMPRESA BRASILEIRA DE HEMODERIVADOS E BIOTECNOLOGIA, 2013).

Por outro lado, do ponto de vista do patrimônio arqueológico, cenários de expansão e crescimento remetem a riscos de destruição de bens finitos e não renováveis. Sobre esse tema, Caldarelli (1999) discute as problemáticas relacionadas aos impactos de obras de infraestrutura sobre o patrimônio arqueológico e à possibilidade de impedimento de usufruto desse legado pelas gerações presentes e futuras. No caso do município de Goiana, área que abrange esse estudo, os riscos de destruição do patrimônio arqueológico se expressam em dois cenários distintos: o urbano e o rural. O primeiro se refere, por um lado, à dinâmica da expansão urbana em direção a novos espaços; por outro lado, à transformação do contexto arquitetônico do centro histórico da cidade.

O interesse imobiliário por áreas periféricas à cidade tem aumentado consideravelmente com a chegada de novos empreendimentos industriais. Nas áreas de praia também tem crescido o interesse do setor. Diversas obras de condomínios residenciais estão previstas ou encontramse em andamento. Ocorre que não estão previstos, de acordo com a Lei de Uso e Ocupação do Solo do município (GOIANA, 2004), ou outros instrumentos legais e administrativos, estudos preliminares de arqueologia no intuito de verificar a existência de vestígios arqueológicos nos locais de construção. Empreendimentos de abrangência local, quando tratados isoladamente, geralmente não representam riscos aos bens arqueológicos; no entanto, quando se trata de um processo de expansão urbana em diversas partes do território municipal, a dimensão do potencial de destruição se transforma.

Em se considerando que os efeitos dos impactos do processo de expansão na área urbana se potencializam quando se trata do centro histórico, tal área requer mais cuidados do ponto de vista legal e administrativo. Pela relevância dos monumentos e fatos transcorridos naquela área da cidade, o IPHAN está promovendo o tombamento do Conjunto Urbanístico e Paisagístico do Município de Goiana. A área tombada compreende residências, prédios públicos, estabelecimentos comerciais, igrejas, ruas e avenidas de trânsito intenso. A despeito da sua condição de conjunto tombado, trata-se de uma malha urbana dinâmica, onde residem e trabalham goianenses. A cidade sofre mudanças constantes, além de construções e reformas de espaços a fim adequá-los as necessidades dos seus proprietários e usuários. Tal situação se reflete diretamente sobre o patrimônio arqueológico eventualmente presente sob as edificações e calçamentos. Há relatos de moradores que indicam a ocorrência de vestígios arqueológicos no subsolo de residências e igrejas que passaram por reformas sem acompanhamento de profissionais do IPHAN, atualmente responsável pela preservação da área tombada.

Por outro lado, o cenário rural onde também se verifica o potencial de risco ao patrimônio arqueológico de Goiana, remete essencialmente à expansão industrial em áreas antes ocupadas por campos de cultivo de cana-de-açúcar. A expansão industrial no município é verificada, sobretudo em sua porção leste, nas imediações da Rodovia BR 101. Como já citado, três polos industriais estão sendo instalados na zona rural do município: o polo farmacoquímico, lançado com a instalação da Empresa Brasileira de Hemoderivados e 
Biotecnologia - Hemobrás; o polo automotivo, promovido pela Fábrica da FIAT; e o polo vidreiro, projetado pela Companhia Brasileira de Vidros Planos (CBVP). A localização de sítios arqueológicos nas áreas de implantação de tais empreendimentos indica a necessidade de manutenção da política de licenciamento arqueológico em novas áreas de expansão industrial no município, desconhecidas do ponto de vista arqueológico.

As situações de risco ao patrimônio arqueológico, tanto na área urbana quanto na rural, refletem a ausência de uma Gestão do Patrimônio Arqueológico (GPA). Os óbices identificados conduzem à necessidade de definir e implantar instrumentos de gestão dos bens arqueológicos capazes de equalizar tais problemas. A adoção de uma GPA no âmbito municipal tem demonstrado, em outros municípios brasileiros, que a prevenção de impactos e a preservação dos bens arqueológicos podem ser alcançadas por meio de instrumentos de identificação, documentação, proteção e promoção (Figura 1).

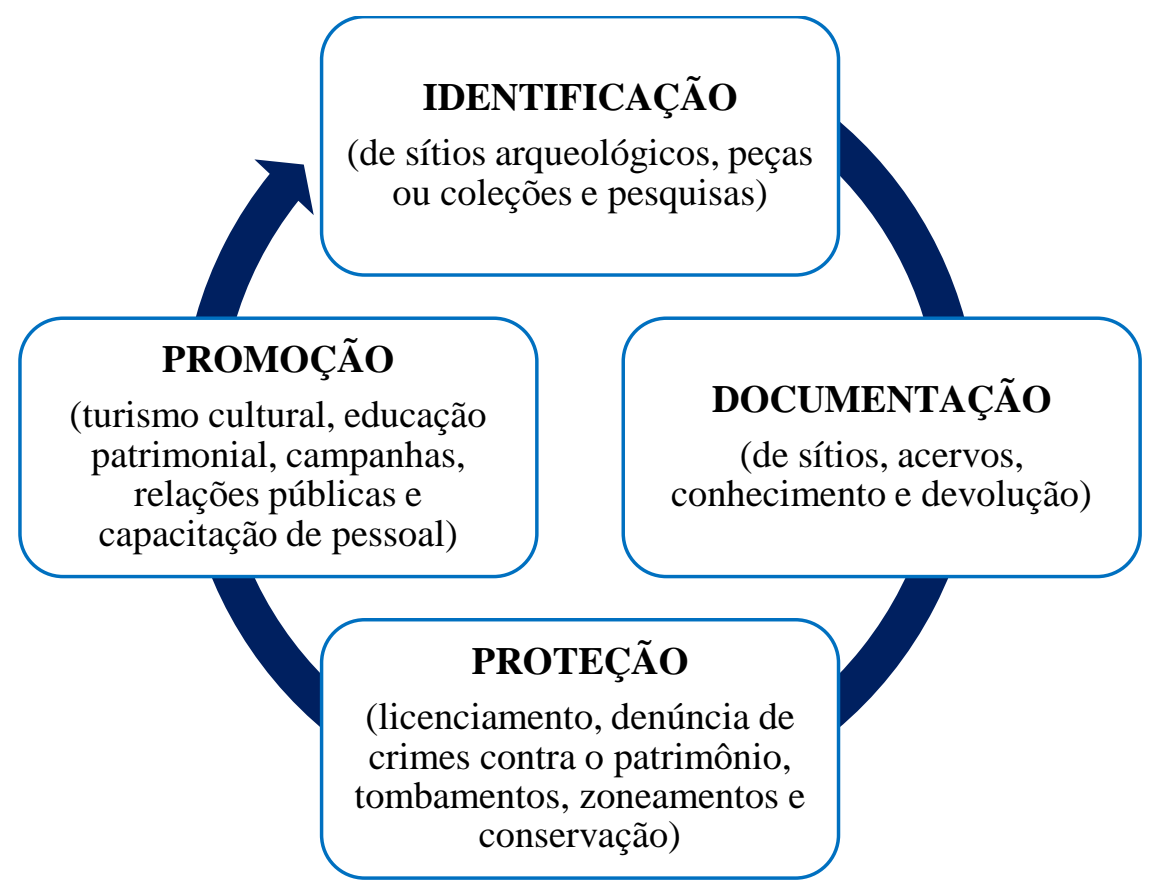

Figura 1 - Esquema dos macroprocessos da gestão do patrimônio arqueológico.Fonte: PARDI, 2002.

Para Pardi (2002: 20-23), a GPA é um conjunto de ações capazes de "otimizar o uso e o retorno à atual geração, a valorização e difusão, bem como a preservação dos sítios ou blocos testemunhos, do acervo gerado, da documentação e do conhecimento produzido para as gerações futuras". A GPA surge, no bojo dessa discussão, como principal meio de preservação desse patrimônio. Apontada como a esfera mais fraca do sistema, a gestão municipal do patrimônio arqueológico constitui a tônica desse estudo. As políticas de gestão do patrimônio arqueológico adotadas em outros municípios brasileiros, analisadas por Pardi (2002), Cali (2005) e Brandi (2009) poderão fornecer as bases para adequação de soluções à realidade goianense no que tange à gestão de seu patrimônio arqueológico. 
Esse estudo buscou identificar instrumentos de gestão do patrimônio arqueológico aplicáveis ao município de Goiana, a fim de subsidiar futuras políticas públicas de preservação dos bens arqueológicos.

\section{Material e Métodos}

O Município de Goiana está localizado na Mesorregião Mata e Microrregião Mata Setentrional do Estado de Pernambuco (Figura 2). Situa-se na região Norte do Estado, limitando-se com o Estado da Paraíba. A leste bordeja o Oceano Atlântico; a sul limita-se com os municípios pernambucanos de Itamaracá, Itapissuma e Igarassu; e a oeste com Itaquitinga, Condado e Itambé.
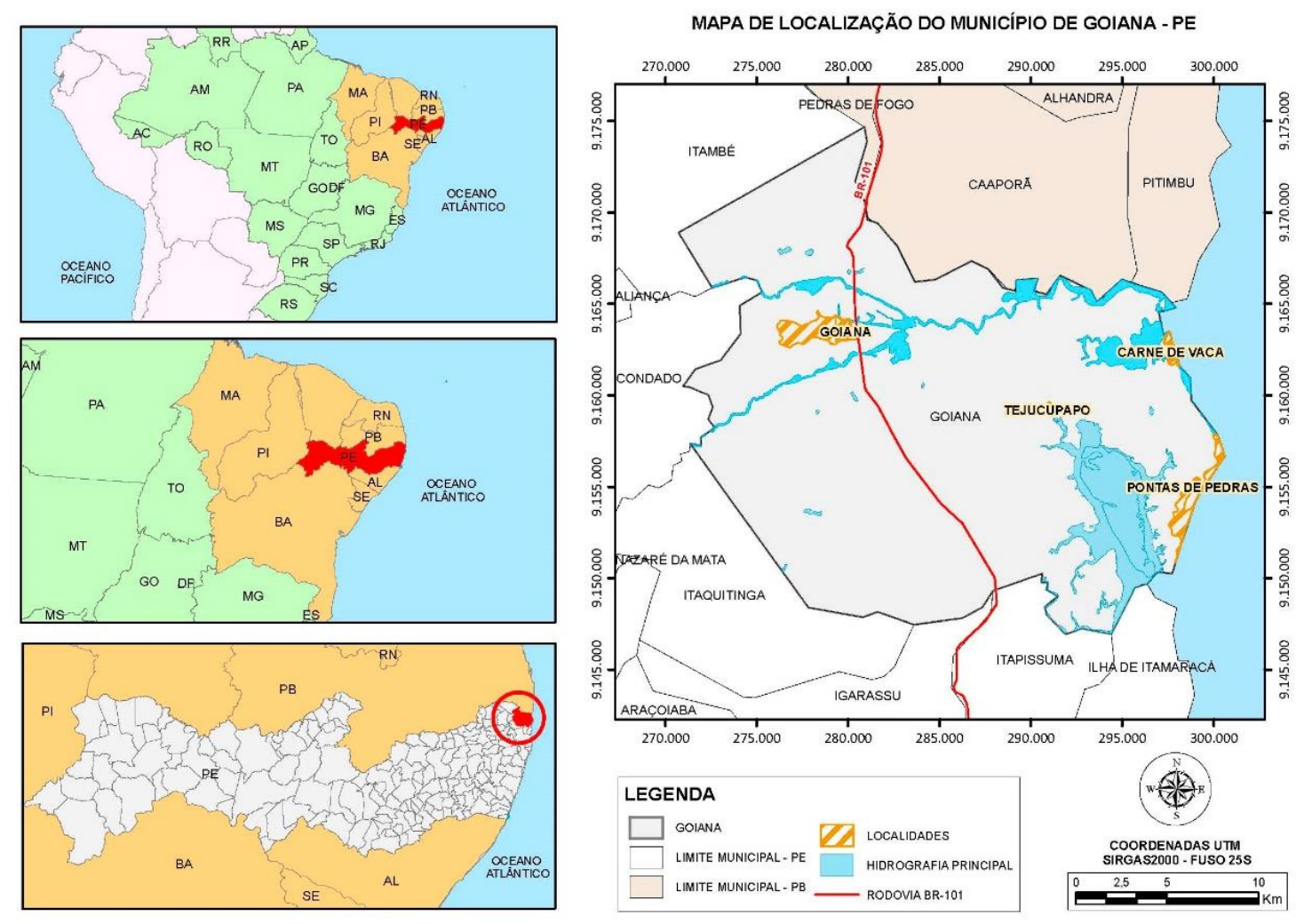

Figura 2 - Mapa de localização do Município de Goiana, Pernambuco. Fonte da base cartográfica: IBGE, 2010. Autor: Daniel Quintino, 2014.

A formação administrativa atual do município de Goiana compreende o Distrito Sede e os distritos de Tejucupapo e Ponta de Pedras. A sede do município, a Cidade de Goiana, está localizada nas coordenadas geográficas $07^{\circ} 33^{\prime} 39^{\prime \prime} \mathrm{S}, 35^{\circ} 00^{\prime} 10^{\prime \prime}$ W (WGS 84) ou UTM 25M, 279022 E, 9163744 N. Situa-se no Vale do rio Goiana, entre os rios Capibaribe-Mirim e Tracunhaém, e dista 65,7 km de Recife, capital do Estado de Pernambuco (CPRM, 2005).

Os métodos utilizados incluem a aquisição de dados secundários, por meio da pesquisa de fontes bibliográficas e documentais em bases de dados acadêmicas, levantamento de dados 
em órgãos públicos ligados ao município de Goiana-PE. Incluem ainda a aquisição de dados primários, por meio de visitas à área de estudo.

A pesquisa de fontes bibliográficas foi realizada por meio de consulta em livros, artigos e periódicos científicos, disponíveis em bibliotecas públicas das redes federal, estadual e municipal, nos municípios de Recife e Goiana. Foram ainda consultados periódicos e publicações disponíveis na internet. O levantamento de fontes documentais consiste, inicialmente, no arrolamento da legislação federal estadual e municipal referente ao tema, disponível em publicações impressas e digitais especializadas.

No Cadastro Nacional de Sítios Arqueológicos do IPHAN foram consultados os registros dos sítios arqueológicos identificados no município de Goiana. O levantamento de dados secundários relativo às ocorrências arqueológicas registradas anteriormente à implantação do atual CNSA/IPHAN foi efetuado por meio de fontes da documentação textual secundária e do banco de dados do Laboratório de Arqueologia da UFPE.

A pesquisa incluiu o levantamento na Prefeitura Municipal de Goiana, onde foi aplicado um questionário de avaliação dos instrumentos de gestão do patrimônio cultural. O questionário, direcionado à Secretaria de Cultura, foi atendido pelo Chefe de Departamento de Promoção ao Turismo da Secretaria Municipal de Turismo e Desenvolvimento Artístico Cultural da Prefeitura de Goiana, José Ítalo César da Cunha, que autorizou a divulgação das informações. Também foi aplicado questionário junto aos integrantes da Divisão de Pesquisa Histórica (DPH), Eliton Pereira e Priscila Santos.

Por último, a pesquisa de campo buscou obter dados espaciais dos sítios históricos e arqueológicos, visando o levantamento de informações não privilegiadas nos registros oficiais ou sequer citadas nas demais fontes. Buscou ainda verificar, no contexto local, as dificuldades de preservação de tais bens e as possibilidades de implantação de instrumentos de gestão.

Os dados obtidos foram analisados, sobretudo, de modo a identificar e caracterizar os sítios arqueológicos, em termos de sua natureza, contexto sistêmico, significância e potencial de preservação e promoção.

\section{Instrumentos de Gestão do Patrimônio Arqueológico}

Tendo em vista o risco potencial de processos destrutivos sobre o patrimônio arqueológico, em função de projetos desenvolvimentistas e considerando que a legislação municipal exige a proteção desses bens, torna-se imperativa a adoção de instrumentos de gestão desse patrimônio. No entanto, o município deverá contar com uma estrutura administrativa básica que viabilize a implantação da GPA. Para Cali (2005), a estrutura administrativa básica necessária para garantir o pleno desenvolvimento da GPA compreende:

a) Conselho Municipal de Patrimônio Cultural;

b) Lei Municipal de Arqueologia (pode estar inserida em outras leis);

c) Órgão técnico formado por profissionais capacitados (Departamento de Patrimônio Histórico, Setor ou Núcleo de Arqueologia etc.); 
d) Museu Municipal (ou similar) dirigido ou assessorado por museólogo;

e) Profissional da área de Arqueologia no quadro permanente ou até mesmo como consultor

Atualmente a Prefeitura Municipal de Goiana possui uma Secretaria de Turismo e Desenvolvimento Artístico Cultural - SETUR, localizada no centro da cidade. Cabe àquele Órgão atender às determinações constantes no Parágrafo 4으, Art. 185 da Lei Orgânica, segundo o qual "ao município cumpre proteger os bens de valor histórico, artístico e cultural, os monumentos, as paisagens naturais notáveis e os sítios arqueológicos". De acordo com informação cedida pelo Chefe de Departamento de Promoção ao Turismo, da Secretaria Municipal de Turismo e Desenvolvimento Artístico Cultural da Prefeitura de Goiana, José Ítalo César da Cunha, por meio de questionário, o corpo administrativo municipal não dispõe de um conselho, órgão técnico ou arqueólogo para a gestão do patrimonial cultural.

A falta de estrutura administrativa básica e a ausência de políticas públicas efetivas para o segmento da cultura no município lhe conferem uma situação de fragilidade diante das questões culturais (EMPRESA BRASILEIRA DE HEMODERIVADOS E BIOTECNOLOGIA, 2013). Acrescente-se aí a ausência de instrumentos de gestão do patrimônio cultural arqueológico como fator aglutinante da situação descrita acima. Tais instrumentos, de acordo com Miranda (2006), podem ser de natureza administrativa, jurídica e legal. A classificação aqui adotada corresponde ao esquema da GPA, isto é, instrumentos de identificação, documentação, proteção e promoção do patrimônio arqueológico. A seguir, serão abordados os principais instrumentos propostos e/ou adotados em municípios brasileiros, com base nos estudos de Juliani (1993), Pardi (2002), Chmyz e Brochier (2004), Cali (2005) e Delforge (2010).

\section{Inventário}

O inventário constitui instrumento de identificação do patrimônio arqueológico (Cali, 2005). Segundo Miranda (2006), o inventário é um instrumento de identificação e registro dos bens culturais, por meio de critérios técnico-científicos. Ao analisar os casos dos municípios de São Paulo-SP e Goiânia-GO, Pardi (2002) aponta como primeiro passo de qualquer município a prospecção e o registro dos sítios existentes em seu território, que podem ser efetuados com pessoal temporário. Segundo a autora, os resultados dessas ações preliminares deverão fundamentar uma avaliação da necessidade de implantação de um sistema de manutenção dos bens arqueológicos eventualmente identificados. Após a análise dos dados obtidos em sua pesquisa, Pardi (2002) propõe um esforço das políticas públicas no sentido de realizar o mapeamento qualitativo e quantitativo das áreas e temas sobre os quais não se produziu conhecimento, como uma diretriz para a política e pesquisa para o setor.

Em outro estudo, Delforge (2010), utilizou o Sistema de Informações Geográficas (SIG) para elaboração do inventário dos sítios arqueológicos do Estado de Minas Gerais. De acordo com o autor, a maioria dos SIGs voltados ao gerenciamento do patrimônio arqueológico desenvolvem as funções de inventário e de gerenciamento de banco de dados. A elaboração do inventário associado à análise espacial da distribuição e atributos dos sítios arqueológicos poderá suscitar 
uma série de considerações relevantes para o gerenciamento dos bens arqueológicos no Estado (Delforge, 2010).

Do ponto de vista do patrimônio arqueológico de Goiana, não foi localizada na literatura institucional e acadêmica qualquer inventário dos bens dessa natureza. Por outro lado, considerando o panorama cultural mais amplo, a Fundarpe realizou em 2005 o Inventário do Patrimônio Cultural da Mata Norte do Estado de Pernambuco, onde se insere o município de Goiana (Fundarpe, 2005). Foram listados bens materiais e imateriais de relevância para a população. Do ponto de vista dos bens de natureza material, foram elencados edifícios isolados, conjuntos urbanos, capelas, igrejas e engenhos. Entretanto, tal Inventário não sinalizou sítios arqueológicos, nem tampouco conduziu a ações efetivas de preservação dos bens culturais destacados.

\section{Zoneamentos arqueológicos}

O zoneamento constitui instrumento de identificação do patrimônio arqueológico amplamente divulgado no mundo. No Brasil, grande parte das políticas públicas de GPA tem adotado o estabelecimento de zoneamento arqueológico (Cali, 2005). Este instrumento requer levantamentos de dados primários e secundários, multidisciplinares, relativos aos aspectos ambientais, históricos e arqueológicos de uma determinada área, que resultam na definição de zonas de potencial arqueológico reconhecido, que passam a ser protegidas pelo Poder Público. Esse instrumento está estritamente relacionado ao conceito de potencial arqueológico (Juliani, 1993). A execução de zoneamentos arqueológicos geralmente subsidia cartas temáticas e leis municipais.

De acordo com o Plano Diretor de Desenvolvimento Urbano (PDDU) do município de Goiana (GOIANA, 2004), não há áreas definidas como zonas arqueológicas que estejam sob a proteção municipal, estadual ou federal. Entretanto, foram estabelecidas as Zonas Especiais de Preservação Cultural (ZEPC). Essas zonas têm por finalidade a proteção histórico-cultural rigorosa e a preservação da paisagem natural e construída, suas escalas e visadas históricas, a preservação da morfologia do assentamento e da vegetação existente. Têm como finalidade ainda promover a requalificação dos espaços públicos e a melhoria e conservação do casario e dos monumentos históricos.

As ZEPC foram assinaladas em mapa anexo ao PDDU e classificadas em:

a) Zonas Especiais de Preservação Histórico-Cultural e Monumental - ZEPHM, localizadas no centro histórico de Goiana;

b) Zonas Especiais de Preservação da Paisagem Histórica e Cultural - ZEPP, localizadas no centro histórico de Goiana, nas imediações do monumento às heroínas de Tejucupapo, nos morros que permitem visadas históricas da paisagem municipal.

Não há qualquer referência direta ou sinalações nos mapas a respeito de sítios arqueológicos. Entretanto, há referência a áreas históricas, como o centro histórico e o "monumento às 
heroínas de Tejucupapo", que detêm interesse do ponto de vista arqueológico, ou seja, em 2004, o Plano Diretor do município passou a funcionar como instrumento de regulamentação do desenvolvimento urbano nas áreas de interesse histórico. Consequentemente, o patrimônio arqueológico porventura contido nessas áreas, mesmo não sendo citado no referido documento, passou a obter proteção municipal indireta.

\section{Cartas temáticas de Arqueologia}

As cartas temáticas de arqueologia ou cartas arqueológicas constituem instrumento de identificação e delimitação amplamente divulgado e adotado em âmbito mundial (CALI, 2005). Para Juliani (1993), "trata-se de um instrumento que vai além de um inventário de indício, mas também de análise e pesquisa, quando busca a compreensão do estado de conservação dos traços de ocupação antrópica do território". Com base nessa premissa, Juliani propôs o zoneamento para compor a Carta Arqueológica do Município de São Paulo-SP, o que, segundo a autora, serviria de apoio ao Conselho Municipal de Preservação do Patrimônio Histórico, Cultural e Ambiental do município. Recomendou ainda a exigência de que empreendimentos de impacto ambiental nas zonas definidas tenham como pré-requisito a execução de estudos arqueológicos por profissionais competentes.

A elaboração de cartas arqueológicas deve ser precedida, segundo Chmyz e Brochier (2004), do reconhecimento e levantamento dos bens culturais existentes e das áreas de interesse onde os mesmos possam ocorrer. Os autores propuseram a elaboração de uma carta arqueológica para o município de Curitiba-PR, a fim de possibilitar a caracterização do potencial arqueológico do território e, a partir de então, definir as zonas de potencial arqueológico do município.

A carta arqueológica também foi apontada como instrumento de gestão do patrimônio arqueológico subaquático nos trabalhos de Rios e Valls (2010) e Freire (2012). No primeiro trabalho, os arqueólogos Carlos Rios e Marcela Valls apresentaram a Carta Arqueológica dos Naufrágios do Litoral de Pernambuco, composta de 25 registros de naufrágios do século XVI, todos ainda a serem descobertos e estudados por arqueólogos (Rios e Valls, 2010). O segundo trabalho é a Carta Arqueológica Subaquática de Sergipe: Inventário Sistemático do Patrimônio Cultural Subaquático, vinculado ao Laboratório de Arqueologia de Ambientes Aquáticos da Universidade Federal de Sergipe, coordenado pelo arqueólogo Gilson Rambelli. Esse projeto busca identificar e inventariar todo o patrimônio arqueológico subaquático do Estado de Sergipe (Freire, 2012).

Do ponto de vista do patrimônio arqueológico de Goiana, não foram localizadas cartas arqueológicas que contemplem os sítios arqueológicos terrestres ou mesmo os naufrágios de sua costa. Até porque, como se viu, a elaboração de tal instrumento requer o conhecimento do potencial arqueológico da região, ainda não alcançado no quadro acadêmico ou institucional. 


\section{Registros de sítios arqueológicos}

A principal forma de documentação do patrimônio arqueológico se dá por meio do registro dos sítios e acervos arqueológicos. Como já mencionado, no âmbito nacional, cabe ao IPHAN o registro desses sítios no CNSA, onde estão registrados mais de 20.000 sítios arqueológicos (IPHAN, 2014). O registro de um sítio é efetuado mediante preenchimento e encaminhamento para o IPHAN de uma ficha de cadastro disponibilizada pelo Instituto. As fichas são avaliadas pela equipe técnica do IPHAN e, se aprovadas, parte dos dados são disponibilizados no CNSA, para consulta pública.

De acordo com a legislação brasileira, o registro de um sítio arqueológico no IPHAN implica em seu tombamento. O local ou o acervo que constitui o sítio passa a ser protegido em nível federal (MIRANDA, 2006). O registro pode ser efetuado por qualquer pesquisador, inclusive do corpo administrativo municipal. No entanto, quase sempre os registros são realizados pelos arqueólogos, após suas pesquisas no município (Pardi, 2002). E, de acordo com Brandi (2009), o Cadastro encontra-se desatualizado há mais de dez anos.

No cadastrado do CNSA existem 38 sítios arqueológicos localizados no município de Goiana (IPHAN, 2014). As informações constantes nas fichas de registro permitiram constatar que tais sítios foram registrados no período de 2005 a 2008 por arqueólogos ligados à Universidade Federal de Pernambuco - UFPE, e estão relacionados a pesquisas de arqueologia preventiva em empreendimentos como rodovia, fábrica e gasoduto (Alves, 2007; Albuquerque, et al., $2008,2011,2012)$. Trata-se de vestígios superficiais, localizados a céu aberto, em grande parte nos canaviais da região.

Além dos sítios registrados no IPHAN, localizou-se nos bancos de dados do Laboratório de Arqueologia da UFPE e nos relatórios técnicos publicados por outras instituições, mais 42 áreas de ocorrências arqueológicas no município. Trata-se, em grande parte, de vestígios localizados em épocas anteriores à criação do CNSA, que permaneceram no acervo da Instituição, entretanto sem registro oficial no banco de dados nacional.

Durante as entrevistas executadas na ocasião da aplicação dos questionários no município de Goiana, constatou-se que os gestores culturais desconhecem a existência de tais registros arqueológicos. Ocorre que o cadastro de novos sítios no IPHAN não envolve o poder municipal, o que leva ao desconhecimento por parte deste.

\section{Leis municipais}

Embora constituam poderoso instrumento de proteção do patrimônio arqueológico, as leis municipais raramente contemplam esses bens (Cali, 2005). Isso se dá, segundo Cali (2005), em razão de três fatores: primeiro, pelo fato de prevalecer o patrimônio edificado na memória institucional, em detrimento do patrimônio natural e arqueológico, pouco visíveis para a sociedade; segundo, pelo fato de a sociedade brasileira não se identificar com o patrimônio pré-colonial, isto é, não edificado; terceiro, pelo desconhecimento dos agentes municipais no tocante à legislação pertinente ao patrimônio arqueológico e à competência municipal. 
Miranda (2006) destaca a possibilidade de utilização da legislação urbanística como instrumento de proteção do patrimônio cultural, sobretudo no tocante ao Estatuto da Cidade (Lei Municipal № 10.257 de 2003), que fixa princípios e diretivas da atuação estatal e municipal. Outro instrumento legal de grande valia para o município é o Plano Diretor, capaz de compatibilizar os setores administrativo, econômico, social e físico do município. Mais que isso, para Miranda (2006), o Plano Diretor deve ser a expressão das aspirações dos munícipes quanto ao progresso do território municipal no seu conjunto cidade/campo.

O município de Goiana não possui lei municipal referente ao patrimônio arqueológico, ou mesmo ao patrimônio cultural. De acordo com Barreto e Lacerda (2007), Goiana carece de um instrumento jurídico capaz de assegurar a preservação do legado existente, objetivando o usufruto e conhecimento também pelas futuras gerações.

\section{Tombamento}

José Eduardo Ramos Rodrigues (apud Miranda, 2006) define o tombamento como sendo "um ato pelo qual o Poder Público declara o valor cultural de coisas móveis ou imóveis, inscrevendo-as no respectivo Livro do Tombo, sujeitando-as a um regime especial que impõe limitações ao exercício de propriedade, com a finalidade de preservá-las". Em âmbito nacional, os bens arqueológicos tombados encontram-se inscritos em sua maioria no Livro do Tombo Arqueológico, Etnográfico e Paisagístico, e alguns no Livro do Tombo das Belas Artes e no Livro do Tombo Histórico.

O município de Goiana conta com a aplicação desse instrumento desde 1938, quando os primeiros monumentos históricos foram tombados: Convento e Igreja de N. S. da Soledade, Convento e Igreja de Santo Alberto de Sicília, Igreja da Ordem Terceira do Carmo, Igreja de N. S. da Conceição, Igreja de N. S. da Misericórdia, Igreja de N. S. do Amparo, Igreja de N. S. do Rosário dos Pretos e Igreja Matriz de N. S. do Rosário (IPHAN, 2013).

Mais recentemente, o IPHAN deu início ao processo de tombamento do conjunto urbanístico da cidade, que compreende os monumentos citados, além de outras edificações, ruas, residências, praças, pontes etc.. A efetivação do tombamento, voltado para o núcleo histórico da cidade e seu entorno, deverá funcionar como instrumento jurídico capaz de assegurar a preservação do legado existente, para fruição e conhecimento também pelas futuras gerações. Os bens contidos na área delimitada passarão a gozar de proteção por meio do IPHAN, para os efeitos previstos no art. 17 do Decreto-Lei no. 25 de 30 de novembro de 1937.

Como um meio de garantir sua posição de destaque na paisagem e ambiência no entorno, o IPHAN instituiu, em 2011, a delimitação de um polígono de proteção e área de entorno dos monumentos (Brasil, 2011).

\section{Vigilância e Fiscalização}


A fim de cumprir o dever constitucional de proteção ao patrimônio cultural arqueológico, os municípios contam com o instrumento do poder de polícia, que viabiliza o controle, a prevenção e a repressão de atividades que possam vir a atentar contra os bens culturais (Miranda, 2006). A falta de vigilância e fiscalização de áreas que apresentam sítios arqueológicos pode levar à destruição desses bens por meio de ações de vandalismo.

Quanto à aplicação de tal instrumento no município de Goiana, a Análise Socioambiental (Empresa Brasileira de hemoderivados e biotecnologia, 2013) apontou a ausência de uma guarda municipal voltada para a segurança patrimonial de bens históricos. Esta situação se estende aos bens arqueológicos, como o Reduto de Tejucupapo (Figura 3 a e b), onde não há vigilância permanente, o que torna o monumento vulnerável a ações de vandalismo e destruição.

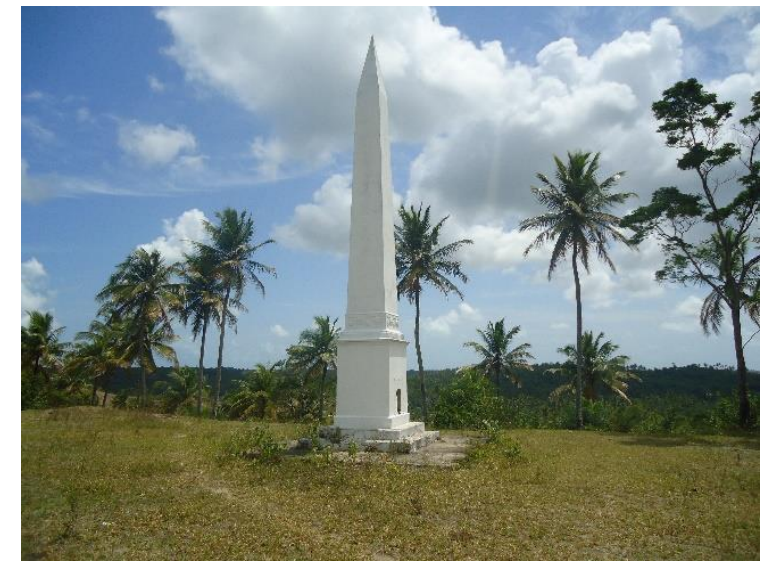

A)

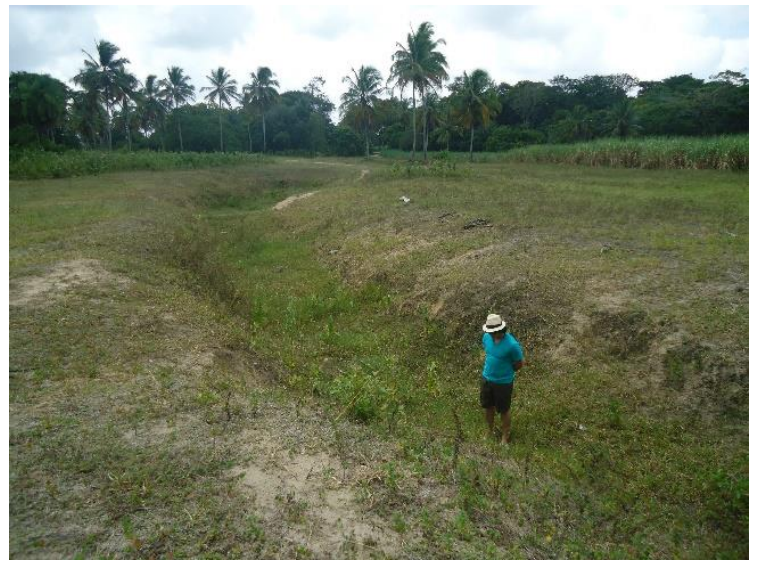

B)

Figura 3 - Condições de vigilância e fiscalização no Reduto de Tejucupapo. A) Monumento em homenagem às heroínas de Tejucupapo. Fonte: Milena Duarte, 2013. B) Trecho do fosso do Reduto de Tejucupapo. Fonte: Milena Duarte, 2013.

\section{Notificação e Orientação}

Outro instrumento de proteção é a notificação acompanhada de orientação aos proprietários de imóveis que possuam sítios arqueológicos. Cali (2005) conta que no município de IlhabelaSP, a Secretaria Municipal de Cultura e a Fundação Arte e Cultura Ilhabela adotaram esse instrumento para notificar e orientar os proprietários, distribuindo folders informativos e educativos a respeito dos sítios arqueológicos, sua natureza, importância e aspectos de proteção legal.

Em Goiana, o IPHAN exerce um trabalho de fiscalização nas áreas tombadas. Entretanto, ao que parece, não há projetos locais que prevejam orientação continuada aos proprietários de imóveis tombados. 


\section{Desapropriação}

Na ótica de Miranda (2006) e Dantas (2010), a desapropriação só deve ser utilizada como última alternativa. Trata-se de privar, de forma coativa, um bem de seu titular, mediante pagamento de indenização. Segundo Miranda (2006), o Estado é muito mais eficiente quando atua como fiscalizador do que como proprietário. Sobre o tema, a Lei n 3.924 (BRASIL, 1961), em seu art. 15, dispõe que em casos especiais, de sítios arqueológicos de significado excepcional, poderá ser promovida a desapropriação do imóvel ou parte dele, por utilidade pública.

Não foram identificados, no município de Goiana, casos de desapropriação em áreas de sítios arqueológicos. Ao contrário, há áreas de interesse cultural situadas em propriedades privadas, como o Reduto de Tejucupapo.

\section{Incentivos e benefícios fiscais e financeiros}

Leis e mecanismos de incentivos fiscais e financeiros têm sido cada vez mais adotadas nos municípios e estados brasileiros (Miranda, 2006). Cali (2005) abordou as políticas municipais de gestão do patrimônio arqueológico, das quais destacou aquelas adotadas nos municípios de Minas Gerais. Naquele Estado, o Instituto Estadual do Patrimônio Histórico e Artístico - IEPHA - é o responsável pelo gerenciamento do patrimônio cultural, inclusive arqueológico, de acordo com o que determina a Lei Estadual no 13.803/00 (Cali, 2005). Esta Lei atribui ao IEPHA a responsabilidade pelo gerenciamento e distribuição de $4 \%$ da arrecadação mensal do ICMS para os municípios que possuam políticas de preservação do patrimônio cultural, de acordo com as diretrizes estabelecidas pelo IEPHA. Assim, cada ação de preservação promovida pelo município corresponde a uma pontuação, que por sua vez é revertida em recursos financeiros para a administração municipal.

Os sítios arqueológicos, entretanto, somente são pontuados pelo ICMS quando são tombados quer pela União, Estado ou Município. Cali aponta falhas no sistema de pontuação adotado, no entanto, conclui que se políticas como essa fossem adotadas pelos demais estados da Federação, certamente o País teria uma realidade bastante diferente da atual, no que se refere à proteção do patrimônio cultural (Cali, 2005).

Não há, no município de Goiana, incentivos ou benefícios fiscais voltados para os proprietários de áreas tombadas. No entanto, no âmbito fiscal, o proprietário poderá recorrer à Lei no 8.313/91 (Brasil, 1991), conhecida como Lei Rouanet. De acordo com a cartilha Fiscalização, publicada pelo IPHAN (2011), no Imposto de Renda de Pessoa Física, podem ser deduzidos $80 \%$ das despesas efetuadas na restauração, preservação e conservação de bens tombados pelo Iphan. Já no caso de pessoa jurídica, podem ser deduzidos $40 \%$ das despesas, segundo a cartilha.

\section{Educação Patrimonial}


A educação patrimonial é um dos mais importantes e eficazes instrumentos de proteção do patrimônio cultural, uma vez que através dela torna-se possível mudar valores e incluir a preservação dos bens culturais na rotina de vida dos cidadãos (Miranda, 2006). Ações de educação patrimonial podem assumir as mais variadas formas, tais como oficinas, palestras, treinamentos, cursos e exposições, e têm como objetivo promover:

- A conscientização das comunidades sobre o valor dos bens culturais materiais e imateriais que as cercam;

- A divulgação eficiente das leis, programas e informações sobre os bens culturais;

- A divulgação de mecanismos de proteção, tais como ação popular e ação civil pública;

- A visibilidade das ações concernentes ao patrimônio e a seus benefícios sociais e econômicos.

No contexto da Arqueologia Preventiva, já mencionada, ações de educação patrimonial têm sido desenvolvidas por equipes de arqueólogos em todo o País. No município de Goiana a atuação não é diferente. Com frequência, esses profissionais buscam seu público alvo nas comunidades e instituições de ensino mais próximas dos empreendimentos. No entanto, constituem ações educativas temporárias e de abrangência restrita.

\section{Aproveitamento turístico}

O aproveitamento turístico dos bens culturais, em especial do patrimônio arqueológico, é um mecanismo capaz de promover a conscientização da população local e de turistas, além de colaborar como recurso para o desenvolvimento do município. Um exemplo de uso desse instrumento é o caso do Projeto de Aproveitamento Turístico dos Sítios Arqueológicos de Ilhabela, onde a população local foi preparada para visitação pública e os sítios arqueológicos tornaram-se atrativo diferenciado no Estado (Cali, 2005). Dezenas de outros sítios arqueológicos históricos e pré-históricos foram transformados em atrativos turísticos, como a Fortaleza de Santa Cruz ou Forte Orange, em Itamaracá-PE, e o Parque Nacional do Catimbau, situado nos municípios de Buíque, Ibimirim e Tupanatinga, em Pernambuco.

Segundo a Análise Socioambiental (Empresa Brasileira de hemoderivados e biotecnologia, 2013), Goiana possui baixa demanda de turistas que visitam áreas históricas. Ainda segundo o documento, as principais dificuldades para visitação desses locais são: a precariedade da infraestrutura de acesso das estradas e a localização da maior parte desses locais em propriedades privadas. Como exemplo mais expressivo dessa situação, tem-se a área do Reduto de Tejucupapo, onde é realizada a apresentação teatral das heroínas de Tejucupapo. Em visita realizada ao local do Reduto de Tejucupapo (Figura 4 a e b), durante o período de alta temporada turística, constatou-se a falta de sinalização, dificuldade de acesso, ausência de fiscalização da guarda municipal e de placas informativas relativas ao monumento. 


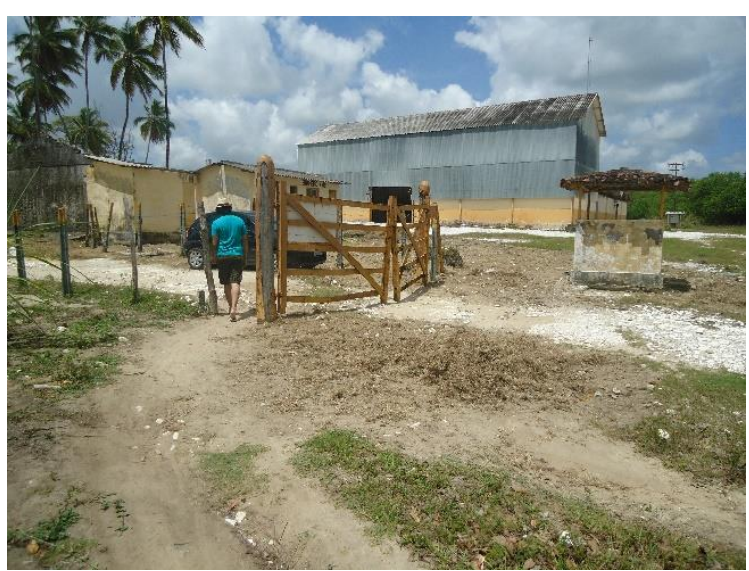

A)

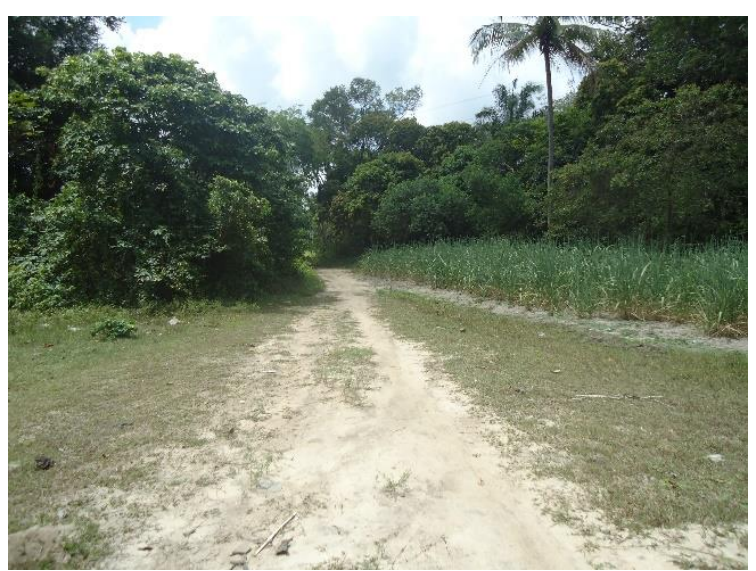

B)

Figura 4: Condições de visitação do Reduto de Tejucupapo. A) Acesso ao Reduto em área privada. Fonte: Milena Duarte, 2013; B) Caminho de acesso até o Reduto, sem sinalização. Fonte: Milena Duarte, 2013.

Também no distrito de São Lourenço, cuja povoação remete ao século XVI, foram identificadas situações de despreparo para atividades turísticas, como a falta de novas placas informativas para a Igreja Matriz (Figura 5), tombada em nível federal, e a utilização da área posterior do monumento como depósito de lixo.

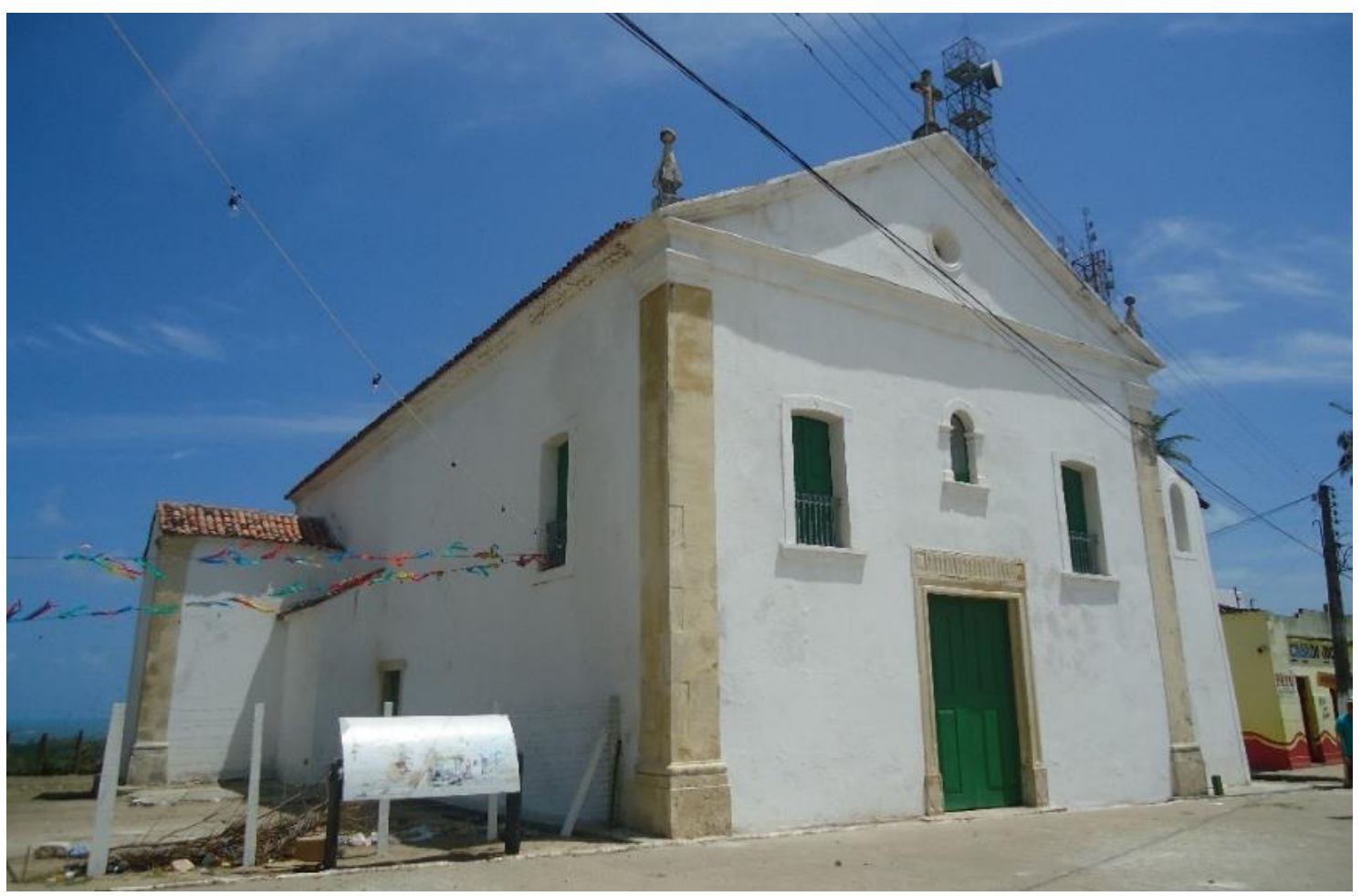

Figura 5: Igreja de São Lourenço de Tejucupapo, com placa informativa danificada. Fonte: Milena Duarte, 2013.

\section{Musealização}


Do ponto de vista da musealização, o patrimônio arqueológico móvel localizado no município de Goiana, durante pesquisas arqueológicas, encontra-se sob a guarda de instituições da Universidade Federal de Pernambuco, quais sejam, o Laboratório de Arqueologia e o Núcleo de Estudos Arqueológicos, com anuência do IPHAN. Por outro lado, parte dos bens arqueológicos localizados fortuitamente pela população, sobretudo na área urbana, têm destinação desconhecida, o que ocorre pela ausência de uma gestão adequada. Algumas peças localizadas em tais condições são enviadas ao Departamento de Pesquisa Histórica da Faculdade de Goiana, onde são identificadas e acondicionadas.

Sobre o tema, o Relatório Socioambiental apontou que não há museus abertos ao público e apontou três fatores negativos para o município: a ausência de uma política municipal voltada para os museus; a inexistência de um espaço físico para abrigar as peças; e a falta de um inventário de catalogação dos objetos de valor histórico e artístico. O Relatório acrescentou ainda a desativação do Instituto Histórico e Geográfico de Goiana (IHGG) como fator de dificuldade ao acesso às memorias e registros da cidade (Empresa Brasileira de Hemoderivados e Biotecnologia, 2013).

Está sendo construído um museu no município para abrigar imagens sacras do século 17, onde terão os devidos cuidados. O futuro Museu de Arte Sacra de Goiana será administrado pelo Serviço Social do Comércio de Pernambuco (SESC-PE), já instalado no município. Será, portanto, o primeiro espaço preparado para abrigar peças de valor cultural em Goiana.

\section{Discussão e Considerações Finais}

A análise dos instrumentos de gestão do patrimônio arqueológico no município de Goiana apontou para a situação descrita por Pardi (2002), no que se refere ao desconhecimento das responsabilidades e competências municipais neste setor. Apontou ainda a ausência ou a ineficiência de alguns instrumentos do sistema da GPA, previstos em cada etapa do processo operacional: identificação, documentação, proteção e promoção.

Do ponto de vista dos instrumentos de identificação, a serem implantados na primeira etapa da GPA, o município não dispõe de inventário, zoneamento ou carta temática relativa ao patrimônio arqueológico. À luz dos estudos de Delforge (2010) e Pardi (2002), a realização do inventário do patrimônio arqueológico do município, preferencialmente com base no Sistema de Informações Geográficas, é fundamental para a identificação e caracterização dos bens dessa natureza, a fim de subsidiar ações futuras de preservação. A inventariação dos bens e sua atualização permanente evitam o desconhecimento ou mesmo o esquecimento mencionados por Brandi (2009). Este seria, portanto, o primeiro passo a ser trilhado pelo município.

No que tange à documentação do patrimônio arqueológico, o CNSA/IPHAN constitui, atualmente, a principal forma de documentação do patrimônio arqueológico, embora desatualizado, a que se referiu Brandi (2009). O levantamento constatou a existência de sítios arqueológicos localizados no município de Goiana, ainda não cadastrados no CNSA, legitimando a situação descrita por Brandi. A solução indicada por Delforge (2010) para esse 
problema é a solicitação direta do IPHAN às instituições envolvidas nas pesquisas anteriores ao Cadastro, a fim de registrar e documentar tais sítios arqueológicos.

Por outro lado, quanto à proteção dos bens arqueológicos, nenhuma política de preservação é observada dentro do planejamento territorial. Se a competência legal e administrativa do município no que tange ao patrimônio arqueológico inclui sua proteção, o principal documento da ordenação territorial, o Plano Diretor Municipal, deveria considerar os locais de interesse arqueológico no zoneamento das áreas especiais do patrimônio cultural. Todavia, como apontou a "Análise participativa da realidade socioambiental de Goiana-PE" (EMPRESA BRASILEIRA DE HEMODERIVADOS E BIOTECNOLOGIA, 2013), há uma demanda urgente de revisão do documento, que além de não considerar as áreas arqueológicas que carecem de proteção, não faz referências ao processo de crescimento econômico impulsionado pela chegada de grandes empreendimentos.

A proteção do patrimônio arqueológico eventualmente presente na área urbana de Goiana conta, de fato, com a lei do tombamento do centro histórico como aliado. Entretanto, a fim de garantir o cumprimento da lei e preservar os bens históricos e arqueológicos, a população residente na área protegida necessita ser orientada sobre seus direitos e deveres, a exemplo do projeto implantado em Ilhabela-SP (CALI, 2005). Ademais, a implantação de uma guarda municipal voltada para a segurança patrimonial de bens históricos e arqueológicos foi apontada pela Hemobrás (EMPRESA BRASILEIRA DE HEMODERIVADOS E BIOTECNOLOGIA, 2013) como medida urgente para o município.

Outra medida que poderá trazer resultados positivos do ponto de vista da preservação dos bens culturais é a promoção, por parte do Poder Público Estadual, de incentivos e benefícios ficais e financeiros aos municípios que implantarem medidas de proteção, tal qual a dinâmica adotada no Estado de Minas Gerais, defendida por Cali (2005).

Ainda no que tange à proteção do patrimônio arqueológico, de acordo com Pardi (2002), uma medida preventiva eficaz, capaz de prevenir os efeitos dos impactos, é a realização de estudos arqueológicos que permitam a produção de conhecimento científico sobre os processos culturais ocorridos no passado. Medidas dessa natureza são capazes de garantir a preservação da memória nacional, regional e local, sem, no entanto, impedir o crescimento econômico.

Por último, as ações de promoção, como a educação patrimonial desenvolvida, sobretudo por meio de projetos de arqueologia preventiva, têm abrangência restrita junto ao grande público. Ações continuadas e de alcance mais amplo junto à sociedade, capazes de "incluir a preservação dos bens culturais na rotina de vida dos cidadãos", como considerou Miranda (2006), teriam resultados mais eficazes.

Outro instrumento de promoção, o aproveitamento turístico, requer um redimensionamento na agenda política municipal. Afinal, como foi apontado pela "Análise participativa da realidade socioambiental de Goiana-PE" (EMPRESA BRASILEIRA DE HEMODERIVADOS E BIOTECNOLOGIA, 2013), com a nova fase de expansão e consolidação de novos empreendimentos, a demanda por turismo tende a aumentar, por isso o cuidado com o patrimônio cultural e o meio ambiente devem ser prioritários. A inclusão de sítios históricos e 
arqueológicos nos roteiros rurais e gastronômicos é válida, desde que garanta a preservação dos bens culturais.

Considerado por Pardi (2002) como um instrumento de promoção "expressivo", a instalação de um museu no município poderá ser o primeiro passo de uma série de ações necessárias à gestão do patrimônio arqueológico de Goiana. O acervo oriundo de pesquisas realizadas no município poderá ser transferido ao município, desde que este demonstre interesse e obtenha consonância do IPHAN.

O presente artigo constatou que dos 13 instrumentos analisados, 8 não são aplicados no município de Goiana. São eles: inventário, zoneamento arqueológico, carta arqueológica, lei municipal, vigilância e fiscalização, notificação e orientação, desapropriação e incentivos fiscais. Cinco instrumentos são parcialmente aplicados ou apresentam falhas de execução, a saber: registro de sítio arqueológico, tombamento, educação patrimonial, aproveitamento turístico e musealização.

Algumas questões identificadas no município levam à manutenção da condição de risco ao patrimônio arqueológico:

- O poder público municipal não dispõe de quadro técnico capacitado na área de Arqueologia e Patrimônio, bem como de estrutura administrativa e operacional para a gestão das demandas culturais históricas e arqueológicas;

- Não há inventários, cartas ou quaisquer levantamentos sistematizados em posse do poder público local, ou mesmo uma comunicação bilateral entre gestores municipais e o IPHAN, responsável pelo cadastro e gerenciamento dos sítios arqueológicos;

- Não há espaços para pesquisa e manejo do material arqueológico, como laboratórios ou museus, onde possam atuar gestores e pesquisadores;

- Há uma carência da presença de técnicos do IPHAN, sobretudo nas áreas protegidas e monumentos tombados, onde frequentemente surgem achados fortuitos que carecem de atendimento arqueológico emergencial;

- A nova fase de expansão industrial desvia os interesses políticos governamentais para as questões de infraestrutura em detrimento das questões sociais e culturais;

- Não há diálogo entre as partes envolvidas no processo (IPHAN, FUNDARPE, órgãos municipais culturais, pesquisadores e sociedade), no sentido de buscar soluções para as questões complicadoras do patrimônio cultural de interesse arqueológico.

Espera-se, com esse estudo, estimular a reflexão a respeito do patrimônio arqueológico no município de Goiana, as possibilidades de preservação e de manejo do conhecimento arqueológico e da cultura material das sociedades passadas.

\section{Referências}


ALBUQUerque, M.; LUCENA, V.; DUARTE, M. Diagnóstico e Avaliação de Impactos sobre o Patrimônio Cultural na área do Projeto de terraplanagem de 440 hectares a margem da BR 101 N, em Goiana, PE. Arqueolog Pesquisas, set. 2011.

ALBUQUERQUE, M.; LUCENA, V.; DUARTE, M.. Programa de Resgate Arqueológico na área da Fábrica da HEMOBRÁS, Goiana-PE. Relatório Final. Setembro, 2008.

ALBUQUERQUE, M.; LUCENA, V.; DUARTE, M.. Relatório Final do Programa de Diagnóstico, Prospecção, Resgate Arqueológico e de Educação Patrimonial na área do 'Projeto de terraplanagem de 440 hectares a margem da BR 101 N, em Goiana, PE'. Arqueolog Pesquisas, mai. 2012.

ALBUQUeRQUE, M.; LUCENA, V.; WALMSLEY, D. Fortes de Pernambuco: imagens do presente e do passado. Recife: Graftorre, 1999. 204 p., il.

ALVES, C. Estudos Arqueológicos na área do gasoduto Nordestão I - RN, PB e PE. Relatório do Patrimônio Histórico, cultural e Arqueológico na Área do Gasoduto Nordestão. Recife, 2007.

BARRETO, J.; LACERDA, N. "Subsídios para a elaboração de Plano de Gestão da Conservação do Núcleo Histórico de Goiana- PE". In: Olinda: Centro de Estudos Avançados da Conservação Integrada, Textos para Discussão V. 16, Série 1 - Gestão da Conservação Urbana, 2007.

BRANDI, R. de A. Patrimônio Cultural Arqueológico na Gestão Territorial: uma proposta para os municípios da foz do rio Itajaí. (Dissertação de Mestrado) Programa de Pós-Graduação em Engenharia Civil da Universidade Federal de Santa Catarina, Florianópolis, 2009.

BRASIL. Constituição da República Federativa do Brasil, de 5 de outubro de 1988. In: Manuais de Legislação Atlas, 5 ed. - São Paulo: Editora Atlas, 1995.

BRASIL. MINISTÉRIO DA CULTURA. IPHAN. Portaria № 132, de 12 de julho de 2011. Notificação a respeito do tombamento do Conjunto Urbanístico e Paisagístico do Município de Goiana, no Estado de Pernambuco.

BRASIL. Lei no 3.924, de 26 de julho de 1961. Dispõe sobre os monumentos arqueológicos e préhistóricos. Diário Oficial [da República Federativa do Brasil], Brasília, DF, 27 jul. 1961.

BRASIL. Lei no 8.313, de 23 de dezembro de 1991. [Lei Rouanet; Lei Federal de Incentivo à Cultura]. Restabelece princípios da Lei $n^{\circ} 7.505$, de 2 de julho de 1986, institui o Programa Nacional de Apoio à Cultura (Pronac) e dá outras providências. Diário Oficial da União - Seção 1 - 24/12/1991, Página 30261.

CALDARELLI, S. B. “Arqueologia e Avaliação de Impacto Ambiental”. In: IAIA Notícias, 1999.

CALDARELLI, S. B. ; SANTOS, M. do C. M. M. dos. "Arqueologia de Contrato no Brasil”. REVISTA USP, São Paulo, n. 44, p. 52-73, dezembro/fevereiro 1999-2000.

CALI, P. Políticas municipais de gestão do patrimônio arqueológico. Tese (Doutoramento em Arqueologia). Pós-graduação do Museu de Arqueologia e Etnologia da Universidade de São Paulo, 2005.

CHMYZ, I.; BROCHIER, L. L. "Proposta de Zoneamento Arqueológico para o Município de Curitiba", In: Revista de Arqueologia, Setor de Ciências Humanas UFPR, Curitiba, v.8, p.35-60, 2004.

CPRM - Serviço Geológico do Brasil. Projeto cadastro de fontes de abastecimento por água subterrânea. Diagnóstico do município de Goiana, estado de Pernambuco / Organizado [por] João de Castro Mascarenhas, Breno Augusto Beltrão, Luiz Carlos de Souza Junior, Manoel Julio da Trindade G. Galvão, Simeones Neri Pereira, Jorge Luiz Fortunato de Miranda. Recife: CPRM/PRODEEM, 2005.

DANTAS, F. S. Direito Fundamental à Memória. Curitiba: Juruá, 2010.

DELFORGE, A. H. O gerenciamento do patrimônio arqueológico no estado de Minas Gerais utilizando-se Sistemas de Informações Espaciais (SIG). (Dissertação de Mestrado). Programa de Pós-Graduação em 
Tratamento de Informação Espacial da Pontifícia Universidade Católica de Minas Gerais. Belo Horizonte, 2010.

EMPRESA BRASILEIRA DE HEMODERIVADOS E BIOTECNOLOGIA. Análise participativa da realidade socioambiental de Goiana-PE. Recife: Hemobrás, 2013.

FREIRE, L. F. Carta Arqueológica: uma ferramenta de gestão e proteção do patrimônio cultural subaquático para o Baixo Rio São Francisco. In: REVISTA CLIO ARQUEOLÓGICA, v. 27, n.1, Recife, 2012.

FUNDAÇÃO DO PATRIMÔNIO HISTÓRICO E ARTí́STICO DE PERNAMBUCO - FUNDARPE. Panorama Cultural. Diretoria de Preservação Cultural, 2005.

GOIANA. Lei Orgânica do Município de Goiana. Revisada e atualizada até a Emenda no 12/2010. Goiana, 1990.

GOIANA. Plano Diretor de Desenvolvimento Urbano do Município de Goiana. Goiana, 2004.

ICOMOS / ICAHM. Carta de Lausanne, 1990.

IPHAN. Bens Móveis e Imóveis Inscritos nos Livros do Tombo do Instituto do Patrimônio Histórico e Artístico Nacional: 1938-2009. Fevereiro de 2013.

IPHAN. Cadastro Nacional de Sítios Arqueológicos - CNSA - Disponível em http://portal.iphan.gov.br/portal/montaPaginaSGPA.

IPHAN. Fiscalização - orientações para usuários de bens tombados, 2011.

JULIANI, L. de J. C. O. "A Carta Arqueológica como Instrumento de Gestão do Patrimônio Urbano SMC", In: A Questão Ambiental Urbana: Cidade de São Paulo / Prefeitura do Município de São Paulo, Secretaria Municipal do Verde e do Meio Ambiente - São Paulo: A Secretaria, 1993.

MIRANDA, M. P. de S. Tutela do patrimônio cultural brasileiro: doutrina, jurisprudência, legislação. Belo Horizonte: Del Rey, 2006.

PARDI, M. L. F. Gestão de patrimônio arqueológico, documentação e política de preservação. Dissertação (Mestrado Profissionalizante em Gestão do Patrimônio Cultural - Área de Concentração Arqueologia). Universidade Católica de Goiás, Goiânia, 2002.

PERNAMBUCO. Agência Estadual de Planejamento e Pesquisas de Pernambuco - CONDEPE/FIDEM. Estudos dos impactos dos investimentos na economia pernambucana: Unidades da BR FOODS, HEMOBRÁS, Estaleiro Atlântico Sul, Petroquímica Suape e Refinaria Abreu e Lima: uma visão a partir da Matriz Insumo-Produto de Pernambuco - 2005 / Coordenação de Wilson Grimaldi e Júlio César Silva. Recife, 2011.

PERNAMBUCO. Agência Estadual de Planejamento e Pesquisas de Pernambuco - CONDEPE/FIDEM. Norte Metropolitano e Goiana: oportunidades e desafios para o desenvolvimento sustentável. Recife, 2010.

PERNAMBUCO. Constituição do Estado de Pernambuco. Assembleia Legislativa do Estado de Pernambuco, em 18 de dezembro de 2008.

PERNAMBUCO. Decreto № 6.239, de 1 de janeiro de 1980, que Regulamenta a Lei № 7.970, de 18 de janeiro de 1979, que institui o tombamento de bens pelo Estado, e dá outras providências.

RIOS, C.; VALLS, M. “Carta arqueológica dos naufrágios do litoral de Pernambuco: de 1503 a 1600”. In: Revista Navigator, Diretoria do Patrimônio Histórico e Documentação da Marinha, v. 6, n. 12, 2010. 